\title{
Chemists synthesize a natural-born killer
}

It took 22 years and involved 64 chemical transformations, but chemists have finally succeeded in making a synthetic version of the natural insecticide azadirachtin. It is the longest-running project that Steven Ley's group, at the University of Cambridge, UK, has ever completed.

But it is unlikely that this 'total synthesis' will ever be repeated - even though Ley is confident that he could more than halve the number of steps - because it is much easier to extract azadirachtin from the seeds of the Indian neem tree (Azadirachta indica). For some chemists, these sorts of tours de force seem increasingly irrelevant.

Natural-product synthesis emerged in the 1820s when Friedrick Wöhler synthesized urea, showing for the first time that a chemical made by nature could be recreated in the lab. It has spawned some serendipitous discoveries:

"There is nothing more noble than what we're trying to achieve." William Perkin made the first synthetic dye, mauveine, in 1856 while trying to synthesize the drug quinine at the Royal College of Chemistry, now part of Imperial College London.

But for the past 20 years there's been a growing consensus among chemists that the routes to some target molecules are so complicated and low-yielding that making them in this way is pointless. Synthetic azadirachtin is unlikely ever to be used. "Sixty-four steps is not going to be possible for anyone to make on any scale," says Gemma Veitch, who helped derive the synthesis.

In fact, the trend now is to extract pesticides from their natural sources and to move away from either naturally based or purely synthetic compounds such as DDT (dichlorodiphenyltrichloroethane), says John Pickett, head of biochemistry research at Rothamsted Research in the United Kingdom.

But Ley insists that his quest was not in vain. "We won't quit now," he says. "We want to understand a lot more about the biology of the compound." He also expects to make simpler, more effective analogues of azadirachtin that lessen some of the sensitivity the compound shows towards light, acids and bases. Ley says he has also identified the protein in insects that binds to azadirachtin, and that without total synthesis, none of these things would have been possible. The full synthesis appears in the journal Angewandte Chemie (G. E. Veitch et al. Angew.Chem. doi:10.1002/ anie.200703027; 2007).

Derek Lowe, a medicinal chemist and author of the blog 'In the pipeline', is a vocal critic of total synthesis. He says that the traditional justifications for the process, such as structure determination, have evaporated as characterization techniques including nuclear magnetic resonance spectroscopy and mass spectrometry have advanced. He also dismisses the need to make complicated molecules, calling it a trophy-grabbing exercise. "Making the molecule just for the sake of being able to do it is a waste of time," he says. "Some groups have lost track of the reason they're doing total synthesis."

"In the past we were peacocks, we liked to show off," Ley admits. But his attitude has changed. "Today it's all about the value of what you do." There is no point in going after "Everest" challenges, he says. "I don't have to

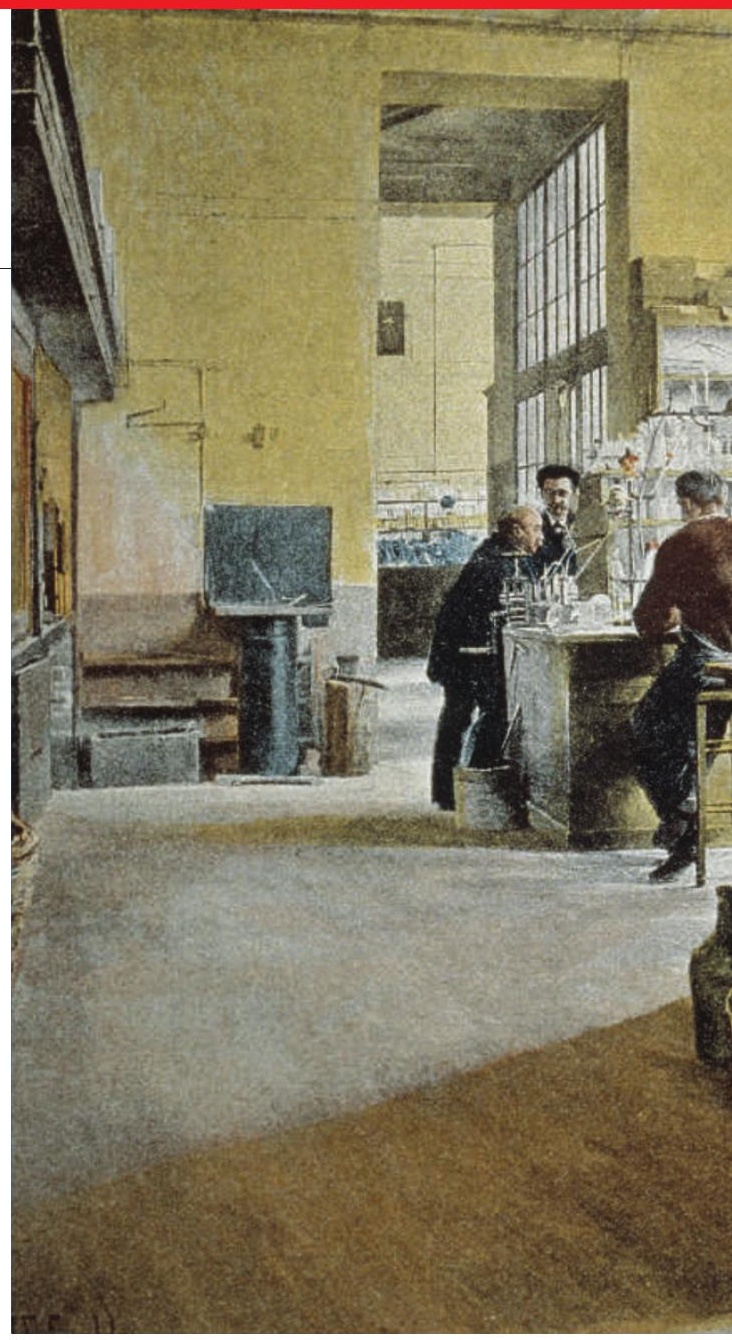

be first; the elegance of the approach is what interests me."

Paul Wender, a synthetic chemist at Stanford University, suggests a different approach. Rather than attempting a very complex molecule, why not design simple but related target molecules, based on the structure and function of the complex natural product, he asks. "This addresses a major problem that many voice about complex molecule synthesis, namely that the targets, although exciting in function, are often too complex to be made in a practical fashion," Wender says.

Other total-synthesis chemists vehemently defend their craft. Phil Baran, from the Scripps Research Institute in La Jolla, California,

\section{A genetic switch for gender bending}

Female mice missing a gene involved in pheromone detection show the same sexual behaviour as males, researchers report this week (T. Kimchi et al. Nature doi:10.1038/ nature06089; 2007).

The striking finding, by Catherine Dulac's group at Harvard University implies that female mice have a 'male behaviour' circuit in their brains, which can be activated by the flick of a single genetic switch.

Female mice genetically engineered to lack a gene called Trpc2 engaged in exclusively male traits, such as pelvic thrusting, male calls and mounting other mice, both female and male. The TRPC2 protein is essential for the functioning of the vomeronasal organ - a part of the mouse nose that is involved in sensing pheromones.

The results prompt a rethink about how the brain regulates sexual behaviour according to gender, but some query whether they could simply be an effect of the lab environment, or of the types of mice used.
Lab conditions, says Dulac, might cause mice to be more limited in their behaviour than they otherwise would be. So, her group tested the same mutant mice under more natural conditions, leaving them in a larger enclosure for a month. The Trpc2-knockout mice still behaved sexually as if they were males.

The genetic make-up of lab mice 
